4

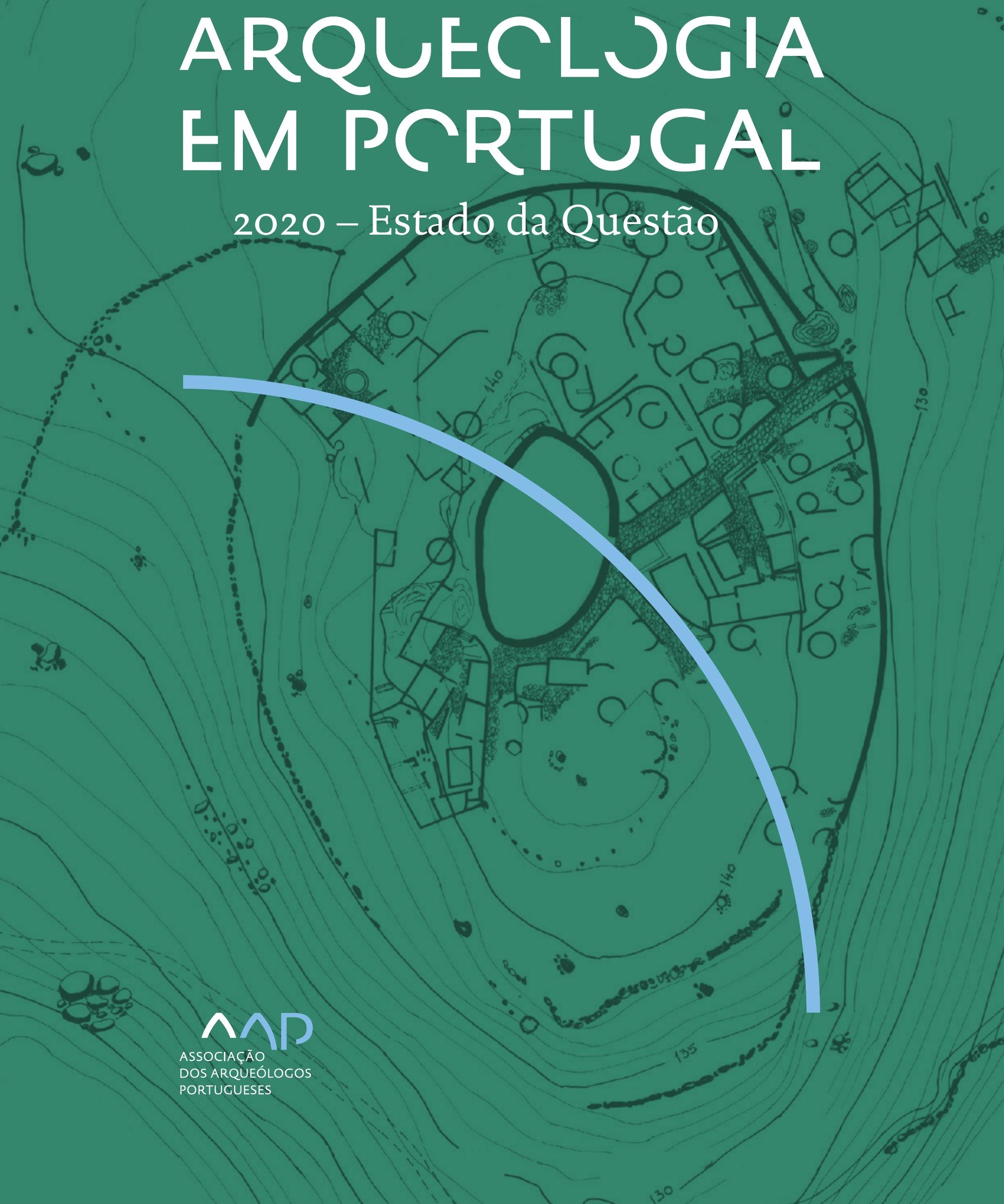


Coordenação editorial: José Morais Arnaud, César Neves e Andrea Martins Design gráfico: Flatland Design

AAP - ISBN: 978-972-9451-89-8

CITCEM - ISBN: 978-989-8970-25-1

Associação dos Arqueólogos Portugueses e CITCEM

Lisboa, 2020

O conteúdo dos artigos é da inteira responsabilidade dos autores. Sendo assim a Associação dos Arqueólogos Portugueses declina qualquer responsabilidade por eventuais equívocos ou questões de ordem ética e legal.

Desenho de capa:

Planta do castro de Monte Mozinho (Museu Municipal de Penafiel).

\section{$\hat{\wedge} \mathrm{P}$}

DOS ARQUEÓLOGOS PORTUGUESES

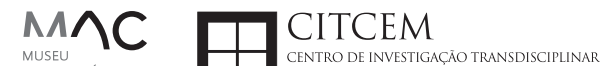
MUSEU
ARQUELLÓGICO
DO CARMO
U.PORTO

FLUP FACULDADE DE LETRAS
UNIVERSIDADE DO PORTO

Apoio

EC para a Ciência 


\section{Índice}

15 Prefácio

José Morais Arnaud

\section{Historiografia e Teoria}

17 Território, comunidade, memória e emoção: a contribuição da história da arqueologia (algumas primeiras e breves reflexões)

Ana Cristina Martins

25 Como descolonizar a arqueologia portuguesa?

Rui Gomes Coelho

41 Arqueologia e Modernidade: uma revisitação pessoal e breve de alguns aspetos da obra homónima de Julian Thomas de 2004

Vítor Oliveira Jorge

57 Dados para a História das Mulheres na Arqueologia portuguesa, dos finais do século XIX aos inícios do século XX: números, nomes e tabelas

Filipa Dimas / Mariana Diniz

73 Retractos da arqueologia portuguesa na imprensa: (in)visibilidades no feminino

Catarina Costeira / Elsa Luís

85 Arqueologia e Arqueólogos no Norte de Portugal Jacinta Bugalhão

101 Vieira Guimarães (1864-1939) e a arqueologia em Tomar: uma abordagem sobre o território e as gentes

João Amendoeira Peixoto / Ana Cristina Martins

115 Os memoráveis? A arqueologia algarvia na imprensa nacional e regional na presente centúria (2001-2019): características, visões do(s) passado(s) e a arqueologia

enquanto marca

Frederico Agosto / João Silva

129 A Evolução da Arqueologia Urbana e a Valorização Patrimonial no Barlavento Algarvio: Os casos de Portimão e Silves

Artur Mateus / Diogo Varandas / Rafael Boavida

\section{Gestão, Valorização e Salvaguarda do Património}

145 O Caderno Reivindicativo e as condições de trabalho em Arqueologia Miguel Rocha / Liliana Matias Carvalho / Regis Barbosa / Mauro Correia / Sara Simões / Jacinta Bugalhão / Sara Brito / Liliana Veríssimo Carvalho / Richard Peace / Pedro Peça / Cézer Santos

155 Os Estudos de Impacte Patrimonial como elemento para uma estratégia sustentável de minimização de impactes no âmbito de reconversões agrícolas Tiago do Pereiro

165 Salvaguarda de Património arqueológico em operações florestais: gestão e sensibilização Filipa Bragança / Gertrudes Zambujo / Sandra Lourenço / Belém Paiva / Carlos Banha / Frederico Tatá Regala / Helena Moura / Jacinta Bugalhão / João Marques / José Correia / Pedro Faria / Samuel Melro

179 Os valores do Património: uma investigação sobre os Sítios Pré-históricos de Arte Rupestre do Vale do Rio Côa e de Siega Verde José Paulo Francisco 
189 Conjugando recursos arqueológicos e naturais para potenciar as visitas ao Geoparque Litoral de Viana do Castelo (Noroeste de Portugal)

Hugo A. Sampaio / Ana M.S. Bettencourt / Susana Marinho / Ricardo Carvalhido

203 Áreas de Potencial Arqueológico na Região do Médio Tejo: Modelo Espacial Preditivo Rita Ferreira Anastácio / Ana Filipa Martins / Luiz Oosterbeek

223 Património Arqueológico e Gestão Territorial: O contributo da Arqueologia para a revisão do PDM de Avis

Ana Cristina Ribeiro

237 A coleção arqueológica do extinto Museu Municipal do Porto - Origens, Percursos e Estudos

Sónia Couto

251 Valpaços - uma nova carta arqueológica

Pedro Pereira / Maria de Fátima Casares Machado

263 Arqueologia na Cidade de Peniche

Adriano Constantino / Luís Rendeiro

273 Arqueologia Urbana: a cidade de Lagos como caso de Estudo Cátia Neto

285 Estratégias de promoção do património cultural subaquático nos Açores. O caso da ilha do Faial

José Luís Neto / José Bettencourt / Luís Borges / Pedro Parreira

297 Carta Arqueológica da Cidade Velha: Uma primeira abordagem

Jaylson Monteiro / Nireide Tavares / Sara da Veiga / Claudino Ramos / Edson Brito /

Carlos Carvalho / Francisco Moreira / Adalberto Tavares

311 Antropologia Virtual: novas metodologias para a análise morfológica e funcional Ricardo Miguel Godinho / Célia Gonçalves

\section{Didáctica da Arqueologia}

327 Como os projetos de Arqueologia podem contribuir para uma comunidade culturalmente mais consciente Alexandra Figueiredo / Claúdio Monteiro / Adolfo Silveira / Ricardo Lopes

337 Educação Patrimonial - Um cidadão esclarecido é um cidadão ativo! Ana Paula Almeida

351 A aproximação da Arqueologia à sala de aula: um caso de estudo no $3^{\circ}$ ciclo do Ensino Básico Luís Serrão Gil

363 Arqueologia 3.o - Pensar e comunicar a Arqueologia para um futuro sustentável Mónica Rolo

377 “Conversa de Arqueólogos" - Divulgar a Arqueologia em tempos de Pandemia Diogo Teixeira Dias

389 Escola Profissional de Arqueologia: desafios e oportunidades Susana Nunes / Dulcineia Pinto / Júlia Silva / Ana Mascarenhas

399 Os Museus de Arqueologia e os Jovens: a oferta educativa para o público adolescente Beatriz Correia Barata / Leonor Medeiros

411 O museu universitário como mediador entre a ciência e a sociedade: o exemplo da secção de arqueologia no Museu de História Natural e da Ciência da Universidade do Porto (MHNC-UP)

Rita Gaspar 
421 Museu de Lanifícios: Real Fábrica de Panos. Atividades no âmbito da Arqueologia Beatriz Correia Barata / Rita Salvado

427 Arqueologia Pública e o caso da localidade da Mata (Torres Novas) Cláudia Manso / Ana Rita Ferreira / Cristiana Ferreira / Vanessa Cardoso Antunes

431 Do sítio arqueológico ao museu: um percurso (também) didático Lídia Fernandes

447 Estão todos convidados para a Festa! E para dançar também... O projecto do Serviço Educativo do Museu Arqueológico do Carmo na $5^{\underline{a}}$ Edição da Festa da Arqueologia Rita Pires dos Santos

459 O “Clã de Carenque”, um projeto didático de arqueologia Eduardo Gonzalez Rocha

469 Mediação cultural: peixe que puxa carroça nas Ruínas Romanas de Troia Inês Vaz Pinto / Ana Patrícia Magalhães / Patrícia Brum / Filipa Santos

481 Didática Arqueológica, experiências do Projeto Mértola Vila Museu Maria de Fátima Palma / Clara Rodrigues / Susana Gómez / Lígia Rafael

\section{Arte Rupestre}

497 Os inventários de arte rupestre em Portugal Mila Simões de Abreu

513 O projeto FIRST-ART - conservação, documentação e gestão das primeiras manifestações de arte rupestre no Sudoeste da Península Ibérica: as grutas do Escoural e Maltravieso Sara Garcês / Hipólito Collado / José Julio García Arranz / Luiz Oosterbeek / António Carlos Silva / Pierluigi Rosina / Hugo Gomes / Anabela Borralheiro Pereira / George Nash / Esmeralda Gomes / Nelson Almeida / Carlos Carpetudo

523 Trabalhos de documentação de arte paleolítica realizados no âmbito do projeto PalæoCôa André Tomás Santos / António Fernando Barbosa / Luís Luís / Marcelo Silvestre / Thierry Aubry

537 Imagens fantasmagóricas, silhuetas elusivas: as figuras humanas na arte do Paleolítico Superior da região do Côa Mário Reis

$55^{1}$ Os motivos zoomórficos representados nas placas de tear de Vila Nova de São Pedro (Azambuja, Portugal) Andrea Martins / César Neves / José M. Arnaud / Mariana Diniz

571 Arte Rupestre do Monte de Góios (Lanhelas, Caminha). Síntese dos resultados dos trabalhos efectuados em 2007-2009 Mário Varela Gomes

599 Gravuras rupestres de barquiformes no Monte de S. Romão, Guimarães, Noroeste de Portugal Daniela Cardoso

613 Círculos segmentados gravados na Bacia do Rio Lima (Noroeste de Portugal): contributos para o seu estudo Diogo Marinho / Ana M.S. Bettencourt / Hugo Aluai Sampaio

631 Equídeos gravados no curso inferior do Rio Mouro, Monção (NW Portugal). Análise preliminar Coutinho, L.M. / Bettencourt, A.M.S / Sampaio, Hugo A.S

645 Paletas na Arte Rupestre do Noroeste de Portugal. Inventário preliminar Bruna Sousa Afonso / Ana M. S. Bettencourt / Hugo A. Sampaio 


\section{Pré-História}

661 O projeto Miño/Minho: balanço de quatro anos de trabalhos arqueológicos Sérgio Monteiro-Rodrigues / João Pedro Cunha-Ribeiro / Eduardo Méndez-Quintas / Carlos Ferreira / Pedro Xavier / José Meireles / Alberto Gomes / Manuel Santonja / Alfredo Pérez-González

677 A ocupação paleolítica da margem esquerda do Baixo Minho: a indústria lítica do sítio de Pedreiras 2 (Monção, Portugal) e a sua integração no contexto regional Carlos Ferreira / João Pedro Cunha-Ribeiro / Sérgio Monteiro-Rodrigues / Eduardo Méndez-Quintas / Pedro Xavier / José Meireles / Alberto Gomes / Manuel Santonja / Alfredo Pérez-González

693 O sítio acheulense do Plistocénico médio da Gruta da Aroeira Joan Daura / Montserrat Sanz / Filipa Rodrigues / Pedro Souto / João Zilhão

703 As sociedades neandertais no Barlavento algarvio: modelos preditivos com recurso aos SIG

Daniela Maio

715 A utilização de quartzo durante o Paleolítico Superior no território dos vales dos rios Vouga e Côa

Cristina Gameiro / Thierry Aubry / Bárbara Costa / Sérgio Gomes / Luís Luís / Carmen Manzano / André Tomás Santos

733 Uma perspetiva diacrónica da ocupação do concheiro do Cabeço da Amoreira (Muge, Portugal) a partir da tecnologia lítica Joana Belmiro / João Cascalheira / Célia Gonçalves

745 Novos dados sobre a Pré-história Antiga no concelho de Palmela. A intervenção arqueológica no sítio do Poceirão I

Michelle Teixeira Santos

757 Problemas em torno de Datas Absolutas Pré-Históricas no Norte do Alentejo Jorge de Oliveira

771 Povoamento pré-histórico nas áreas montanhosas do NO de Portugal: o Abrigo 1 de Vale de Cerdeira Pedro Xavier / José Meireles / Carlos Alves

783 Apreciação do povoamento do Neolítico Inicial na Baixa Bacia do Douro. A Lavra I (Serra da Aboboreira) como caso de estudo Maria de Jesus Sanches

797 O Processo de Neolitização na Plataforma do Mondego: os dados do Sector C do Outeiro dos Castelos de Beijós (Carregal do Sal)

João Carlos de Senna-Martinez / José Manuel Quintã Ventura / Andreia Carvalho / Cíntia Maurício

823 Novos trabalhos na Lapa da Bugalheira (Almonda, Torres Novas) Filipa Rodrigues / Pedro Souto / Artur Ferreira / Alexandre Varanda / Luís Gomes / Helena Gomes / João Zilhão

837 A pedra polida e afeiçoada do sítio do Neolítico médio da Moita do Ourives (Benavente, Portugal)

César Neves

857 Casal do Outeiro (Encarnação, Mafra): novos contributos para o conhecimento do povoamento do Neolítico final na Península de Lisboa.

Cátia Delicado / Carlos Maneira e Costa / Marta Miranda / Ana Catarina Sousa

873 Stresse infantil, morbilidade e mortalidade no sítio arqueológico do Neolítico Final/ Calcolítico ( $4^{\circ}$ e $3^{\circ}$ milénio a.C.) do Monte do Carrascal 2 (Ferreira do Alentejo, Beja) Liliana Matias de Carvalho / Sofia N. Wasterlain 
885 Come together: O Conjunto Megalítico das Motas (Monção, Viana do Castelo) e as expressões Campaniformes do Alto Minho Ana Catarina Basílio / Rui Ramos

899 Trabalhos arqueológicos no sítio Calcolítico da Pedreira do Poio Carla Magalhães / João Muralha / Mário Reis / António Batarda Fernandes

913 O sítio arqueológico de Castanheiro do Vento. Da arquitectura do sítio à arquitectura de um território João Muralha Cardoso

925 Estudo zooarqueológico das faunas do Calcolítico final de Vila Nova de São Pedro (Azambuja, Portugal): Campanhas de 2017 e 2018 Cleia Detry / Ana Catarina Francisco / Mariana Diniz / Andrea Martins / César Neves / José Morais Arnaud

943 As faunas depositadas no Museu Arqueológico do Carmo provenientes de Vila Nova de São Pedro (Azambuja): as campanhas de 1937 a 1967 Ana Catarina Francisco / Cleia Detry / César Neves / Andrea Martins / Mariana Diniz / José Morais Arnaud

959 Análise funcional de material lítico em sílex do castro de Vila Nova de S. Pedro (Azambuja, Portugal): uma primeira abordagem Rafael Lima

971 O recinto da Folha do Ouro 1 (Serpa) no contexto dos recintos de fossos calcolíticos alentejanos

António Carlos Valera / Tiago do Pereiro / Pedro Valério / António M. Monge Soares

\section{Proto-História}

987 Produção de sal marinho na Idade do Bronze do noroeste Português. Alguns dados para uma reflexão

Ana M. S. Bettencourt / Sara Luz / Nuno Oliveira / Pedro P. Simões / Maria Isabel C. Alves / Emílio Abad-Vidal

1001 A estátua-menir do Pedrão ou de São Bartolomeu do Mar (Esposende, noroeste de Portugal) no contexto arqueológico da fachada costeira de entre os rios Neiva e Cávado Ana M. S. Bettencourt / Manuel Santos-Estévez / Pedro Pimenta Simões / Luís Gonçalves

1015 O Castro do Muro (Vandoma/Baltar, Paredes) - notas para uma biografia de ocupação da Idade do Bronze à Idade Média

Maria Antónia D. Silva / Ana M. S. Bettencourt / António Manuel S. P. Silva / Natália Félix

1031 Do Bronze Final à Idade Média - continuidades e hiatos na ocupação de Povoados em Oliveira de Azeméis João Tiago Tavares / Adriaan de Man

1041 As faunas do final da Idade do Bronze no Sul de Portugal: leituras desde o Outeiro do Circo (Beja)

Nelson J. Almeida / Íris Dias / Cleia Detry / Eduardo Porfírio / Miguel Serra

1055 A Espada do Monte das Oliveiras (Serpa) - uma arma do Bronze Pleno do Sudoeste Rui M. G. Monge Soares / Pedro Valério / Mariana Nabais / António M. Monge Soares

1065 São Julião da Branca (Albergaria-a-Velha) - Investigação e valorização de um povoado do Bronze Final

António Manuel S. P. Silva / Paulo A. P. Lemos / Sara Almeida e Silva / Edite Martins de Sá

1083 Do castro de S. João ao Mosteiro de Santa Clara: notícia de uma intervenção arqueológica, em Vila do Conde Rui Pinheiro 
1095 O castro de Ovil (Espinho), um quarto de século de investigação - resultados e questões em aberto

Jorge Fernando Salvador / António Manuel S. P. Silva

1111 O Castro de Salreu (Estarreja), um povoado proto-histórico no litoral do Entre Douro e Vouga

Sara Almeida e Silva / António Manuel S. P. Silva / Paulo A. P. Lemos / Edite Martins de Sá

1127 Castro de Nossa Senhora das Necessidades (Sernancelhe): uma primeira análise artefactual Telma Susana O. Ribeiro

${ }_{1141}$ A cividade de Bagunte. O estado atual da investigação Pedro Brochado de Almeida

1153 Zoomorfos na cerâmica da Idade do Ferro no NW Peninsular: inventário, cronologias e significado Nuno Oliveira / Cristina Seoane

1163 Vasos gregos em Portugal: diferentes maneiras de contar a história do intercâmbio cultural na Idade do Ferro

Daniela Ferreira

1175 Os exotica da necrópole da Idade do Ferro do Olival do Senhor dos Mártires (Alcácer do Sal) no seu contexto regional

Francisco B. Gomes

\section{Antiguidade Clássica e Tardia}

1191 O uso de madeira como combustível no sítio da Quinta de Crestelos (Baixo Sabor): da Idade do Ferro à Romanização Filipe Vaz / João Tereso / Sérgio Simões Pereira / José Sastre / Javier Larrazabal Galarza / Susana Cosme / José António Pereira / Israel Espi

1207 Cultivos de Época Romana no Baixo Sabor: continuidade em tempos de mudança? João Pedro Tereso / Sérgio Simões Pereira / Filipe Santos / Luís Seabra / Filipe Vaz

1221 A casa romana na Hispânia: aplicação dos modelos itálicos nas províncias ibéricas Fernanda Magalhães / Diego Machado / Manuela Martins

1235 As pinturas murais romanas da Rua General Sousa Machado, n. ${ }^{5}$ 1, Chaves José Carvalho

1243 Trás do Castelo (Vale de Mir, Pegarinhos, Alijó) - Uma exploração agrícola romana do Douro

Tony Silvino / Pedro Pereira

1255 A sequência de ocupação no quadrante sudeste de Bracara Augusta: as transformações de uma unidade doméstica Lara Fernandes / Manuela Martins

1263 Os Mosaicos com decoração geométrica e geométrico-vegetalista dos sítios arqueológicos da área do Conuentus Bracaraugustanus. Novas abordagens quanto à conservação, restauro, decoração e datação Maria de Fátima Abraços / Licínia Wrench

1277 “Casa Romana” do Castro de São Domingos (Cristelos, Lousada): Escavação, Estudo e Musealização Paulo André de P. Lemos

1291 A arqueobotânica no Castro de Guifões (Matosinhos, Noroeste de Portugal): O primeiro estudo carpológico

Luís Seabra / Andreia Arezes / Catarina Magalhães / José Varela / João Pedro Tereso 
1305 Um Horreum Augustano na Foz do Douro (Monte do Castelo de Gaia, Vila Nova de Gaia) Rui Ramos

1311 Ponderais romanos na Lusitânia: padrões, formas, materiais e contextos de utilização Diego Barrios Rodríguez

1323 Um almofariz centro-itálico na foz do Mondego

Marco Penajoia

1335 Estruturas romanas de Carnide - Lisboa Luísa Batalha / Mário Monteiro / Guilherme Cardoso

1347 O contexto funerário do sector da "necrópole NO" da Rua das Portas de S. Antão (Lisboa): o espaço, os artefactos, os indivíduos e a sua interconectividade na interpretação do passado Sílvia Loja, José Carlos Quaresma, Nelson Cabaço, Marina Lourenço, Sílvia Casimiro, Rodrigo Banha da Silva, Francisca Alves-Cardoso

${ }_{1361}$ Povoamento em época Romana na Amadora - resultados de um projeto pluridisciplinar Gisela Encarnação / Vanessa Dias

1371 A Arquitectura Residencial em Mirobriga (Santiago do Cacém): contributo a partir de um estudo de caso Filipe Sousa / Catarina Felício

${ }_{1385}$ O fim do ciclo. Saneamento e gestão de resíduos nos edifícios termais de Mirobriga (Santiago do Cacém)

Catarina Felício / Filipe Sousa

1399 Balsa, Topografia e Urbanismo de uma Cidade Portuária Vítor Silva Dias / João Pedro Bernardes / Celso Candeias / Cristina Tété Garcia

1413 No Largo das Mouras Velhas em Faro (2017): novas evidências da necrópole norte de Ossonoba e da sua ocupação medieval Ricardo Costeira da Silva / Paulo Botelho / Fernando Santos / Liliana Nunes

1429 Instrumentos de pesca recuperados numa fábrica de salga em Ossonoba (Faro) Inês Rasteiro / Ricardo Costeira da Silva / Paulo Botelho

1439 A Necrópole Romana do Eirô, Duas Igrejas (Penafiel): intervenção arqueológica de 2016 Laura Sousa / Teresa Soeiro

1457 Ritual, descarte ou afetividade? A presença de Canis lupus familiaris na Necrópole Noroeste de Olisipo (Lisboa)

Beatriz Calapez Santos / Sofia Simões Pereira / Rodrigo Banha da Silva / Sílvia Casimiro / Cleia Detry / Francisca Alves Cardoso

1467 Dinâmicas económicas em Bracara na Antiguidade Tardia Diego Machado / Manuela Martins / Fernanda Magalhães / Natália Botica

1479 Cerâmicas e Vidros da Antiguidade Tardia do Edifício sob a Igreja do Bom Jesus (Vila Nova de Gaia) Joaquim Filipe Ramos

1493 Novos contributos para a topografia histórica de Mértola no período romano e na Antiguidade Tardia Virgílio Lopes

\section{8. Época Medieval}

1511 Cerâmicas islâmicas no Garb setentrional "português": algumas evidências e incógnitas Constança dos Santos / Helena Catarino / Susana Gómez / Maria José Gonçalves / Isabel Inácio / Gonçalo Lopes / Jacinta Bugalhão / Sandra Cavaco / Jaquelina Covaneiro / Isabel Cristina Fernandes / Ana Sofia Gomes 
1525 Contributo para o conhecimento da cosmética islâmica, em Silves, durante a Idade Média Rosa Varela Gomes

1537 Yábura e o seu território - uma análise histórico-arqueológica de Évora entre os séculos VIII-XII José Rui Santos

1547 A encosta sul do Castelo de Palmela - resultados preliminares da escavação arqueológica Luís Filipe Pereira / Michelle Teixeira Santos

1559 A igreja de São Lourenço (Mouraria, Lisboa): um conjunto de silos e de cerâmica medieval islâmica

Andreia Filipa Moreira Rodrigues

1571 O registo material de movimentações populacionais no Médio Tejo, durante os séculos XII-XIII. Dois casos de "sunken featured buildings", nos concelhos de Cartaxo e Torres Novas Marco Liberato / Helena Santos / Nuno Santos

1585 O nordeste transmontano nos alvores da Idade média. Notas para reflexão Ana Maria da Costa Oliveira

1601 Sepulturas escavadas na rocha do Norte de Portugal e do Vale do Douro: primeiros resultados do Projecto SER-NPVD

Mário Jorge Barroca / César Guedes / Andreia Arezes / Ana Maria Oliveira

1619 "Portucalem Castrum Novum" entre o Mediterrâneo e o Atlântico: o estudo dos materiais cerâmicos alto-medievais do arqueossítio da rua de D. Hugo, nํ. 5 (Porto) João Luís Veloso

1627 A Alta Idade Média na fronteira de Lafões: notas preliminares sobre a Arqueologia no Concelho de Vouzela

Manuel Luís Real / Catarina Tente

1641 Um conjunto cerâmico medieval fora de portas: um breve testemunho aveirense Susana Temudo

${ }_{1651}$ Os Lóios do Porto: uma perspetiva integrada no panorama funerário da Baixa Idade Média à Época Moderna em meios urbanos em Portugal

Ana Lema Seabra

1659 O Caminho Português Interior de Santiago como eixo viário na Idade Média Pedro Azevedo

1665 Morfologia Urbana: Um exercício em torno do Castelo de Ourém André Donas-Botto / Jaqueline Pereira

1677 Intervenção arqueológica na Rua Marquês de Pombal/Largo do Espírito Santo (Bucelas, Loures)

Florbela Estêvão / Nathalie Antunes-Ferreira / Dário Ramos Neves / Inês Lisboa

1691 O Cemitério Medieval do Poço do Borratém e a espacialidade funerária na cidade de Lisboa Inês Belém / Vanessa Filipe / Vasco Noronha Vieira / Sónia Ferro / Rodrigo Banha da Silva

1705 Um Espaço Funerário Conventual do séc. XV em Lisboa: o caso do Convento de São Domingos da Cidade Sérgio Pedroso / Sílvia Casimiro / Rodrigo Banha da Silva / Francisca Alves Cardoso

\section{9. Época Moderna e Contemporânea}

1721 Arqueologia Moderna em Portugal: algumas reflexões críticas em torno da quantificação de conjuntos cerâmicos e suas inferências históricas e antropológicas Rodrigo Banha da Silva / André Bargão / Sara da Cruz Ferreira

1733 Faianças de dois contextos entre os finais do século XVI e XVIII do Palácio dos Condes de Penafiel, Lisboa

Martim Lopes / Tomás Mesquita 
1747 Um perfil de consumo do século XVIII na foz do Tejo: O caso do Mercado da Ribeira, Lisboa Sara da Cruz Ferreira / Rodrigo Banha da Silva / André Bargão

1761 Os Cachimbos dos Séculos XVII e XVIII do Palácio Mesquitela e Convento dos Inglesinhos (Lisboa)

Inês Simão / Marina Pinto / João Pimenta / Sara da Cruz Ferreira / André Bargão / Rodrigo Banha da Silva

1775 "Tomar os fumos da erua que chamão em Portugal erua sancta». Estudo de Cachimbos provenientes da Rua do Terreiro do Trigo, Lisboa

Miguel Martins de Sousa / José Pedro Henriques / Vanessa Galiza Filipe

1787 Cachimbos de Barro Caulínitico da Sé da Cidade Velha (República de Cabo Verde)

Rodrigo Banha da Silva / João Pimenta / Clementino Amaro

1801 Algumas considerações sobre espólio não cerâmico recuperado no Largo de Jesus (Lisboa) Carlos Boavida

1815 Adereços de vidro, dos séculos XVI-XVIII, procedentes do antigo Convento de Santana de Lisboa (anéis, braceletes e contas)

Joana Gonçalves / Rosa Varela Gomes / Mário Varela Gomes

1837 Da ostentação, luxo e poder à simplicidade do uso quotidiano: arqueologia e simbologia de joias e adornos da Idade Moderna Portuguesa Jéssica Iglésias

1849 Os amuletos em Portugal - dos objetos às superstições: o coral vermelho Alexandra Vieira

1865 Cerâmicas de Vila Franca de Xira nos séculos XV e XVI Eva Pires

1879 «Não passa por teu o que me pertence». Marcas de individualização associadas a faianças do Convento de Nossa Senhora de Aracoeli, Alcácer do Sal Catarina Parreira / Íris Fragoso / Miguel Martins de Sousa

1891 Cerâmica de Leiria: alguns focos de produção

Jaqueline Pereira / André Donas-Botto

1901 Os Fornos na Rua da Biquinha, em Óbidos Hugo Silva / Filipe Oliveira

1909 A casa de Pêro Fernandes, contador dos contos de D. Manuel I: o sítio arqueológico da Silha do Alferes, Seixal (século XVI) Mariana Nunes Ferreira

1921 O Alto da Vigia (Sintra) e a vigilância e defesa da costa Alexandre Gonçalves / Sandra Santos

1937 O contexto da torre sineira da Igreja de Santa Maria de Loures Paulo Calaveira / Martim Lopes

1949 A Necrópole do Hospital Militar do Castelo de São Jorge e as práticas funerárias na Lisboa de Época Moderna Susana Henriques / Liliana Matias de Carvalho / Ana Amarante / Sofia N. Wasterlain

1963 SAND - Sarilhos Grandes Entre dois Mundos: o adro da Igreja e a Paleobiologia dos ossos humanos recuperados

Paula Alves Pereira / Roger Lee Jesus / Bruno M. Magalhães

1975 Expansão urbana da vila de Cascais no século XVII e XVIII: a intervenção arqueológica na Rua da Vitória no 15 a 17

Tiago Pereira / Vanessa Filipe

1987 Novos dados para o conhecimento do Urbanismo de Faro em época Moderna Ana Rosa 
1995 Um exemplo de Arqueologia Urbana em Alcoutim: o Antigo Edifício dos CTT Marco Fernandes / Marta Dias / Alexandra Gradim / Virgílio Lopes / Susana Gómez Martínez

2007 Palácio dos Ferrazes (Rua das Flores/Rua da Vitória, Porto): a cocheira de Domingos Oliveira Maia

Francisco Raimundo

2021 As muitas vidas de um edifício urbano: História, Arqueologia e Antropologia no antigo Recreatório Paroquial de Penafiel Helena Bernardo / Jorge Sampaio / Marta Borges

2035 O convento de Nossa Senhora da Esperança de Ponta Delgada: o contributo da arqueologia para o conhecimento de um monumento identitário João Gonçalves Araújo / N’Zinga Oliveira

2047 Arqueologia na ilha do Corvo... em busca da capela de Nossa Senhora do Rosário Tânia Manuel Casimiro / José Luís Neto / Luís Borges / Pedro Parreira

2059 Perdidos à vista da Costa. Trabalhos arqueológicos subaquáticos na Barra do Tejo Jorge Freire / José Bettencourt / Augusto Salgado

2071 Arqueologia marítima em Cabo Verde: enquadramento e primeiros resultados do projecto CONCHA

José Bettencourt / Adilson Dias / Carlos Lima / Christelle Chouzenoux / Cristóvão Fonseca / Dúnia Pereira / Gonçalo Lopes / Inês Coelho / Jaylson Monteiro / José Lima / Maria Eugénia Alves / Patrícia Carvalho / Tiago Silva

2085 Trabalhos arqueológicos na Cidade Velha (Ribeira Grande de Santiago, Cabo Verde): reflexões sobre um projecto de investigação e divulgação patrimonial André Teixeira / Jaylson Monteiro / Mariana Mateus / Nireide Tavares / Cristovão Fonseca / Gonçalo C. Lopes / Joana Bento Torres / Dúnia Pereira / André Bargão / Aurélie Mayer / Bruno Zélie / Carlos Lima / Christelle Chouzenoux / Inês Henriques / Inês Pinto Coelho / José Lima / Patrícia Carvalho / Tiago Silva

2103 A antiga fortificação de Quelba / Khor Kalba (E.A.U.). Resultados de quatro campanhas de escavações, problemáticas e perspectivas futuras Rui Carita / Rosa Varela Gomes / Mário Varela Gomes / Kamyar Kamyad

2123 Colónias para homens novos: arqueologia da colonização agrária fascista no noroeste ibérico Xurxo Ayán Vila / José Mạ . Señorán Martín 


\title{
OS FORNOS NA RUA DA BIQUINHA, EM ÓBIDOS
}

\author{
Hugo Silva ${ }^{\mathrm{T}}$, Filipe Oliveira ${ }^{\mathrm{T}}$
}

\begin{abstract}
RESUMO
Na sequência dos trabalhos arqueológicos (sondagens e acompanhamento), que decorreram no âmbito da requalificação do edifício n64, na Rua da Biquinha, situada no perímetro extra muralhas do Castelo de Óbidos, foram identificados e intervencionados contextos arqueológicos preservados que retratam a ocupação do local entre finais do séc. XV / princípio do séc. XVI até ao séc. XX.

Estes trabalhos permitiram a identificação de um conjunto de quatro fornos localizados no interior do edifício. Estas estruturas de combustão, de plano sub-circular e possível produção cerâmica, encontravam-se escavada no geológico e tinham associado um escasso acervo material, de cronologia Medieval/Moderna.

Palavras-chave: Óbidos, Fornos, Medieval/Moderno.
\end{abstract}

\begin{abstract}
Following archaeological works (surveys and monitoring), executed during the requalification of a building outside the walls of Óbidos Castle, in Rua da Biquinha, 64, preserved archaeological contexts were identified that depict the occupation of the site between the late $15^{\text {th }} /$ beginning of the $16^{\text {th }}$ century until the $20^{\text {th }}$ century. The works allowed for the identification of a set of four ovens located inside the building. These combustion structures, of sub-circular plan were probably used for pottery production. They were excavated into the bedrock and a small collection of materials of Medieval/Modern chronology were found associated with them.
\end{abstract}

Keywords: Óbidos, Kiln, Medieval/Modern age.

\section{O SÍTIO}

O local intervencionado, situa-se no n־64 da Rua da Biquinha, freguesia de Santa Maria, São Pedro e Sobral da Lagoa, concelho de Óbidos. Localizado fora do espaço amuralhado de Óbidos, na encosta a Este do castelo, o terreno encontra-se hoje ocupado por um edifício de dois pisos, com o nível superior e térreo funcionando como espaço habitacional, e o inferior e o lote a Sul a acolherem áreas de apoio como cocheiras/curral, celeiro ou arrumos.

A natureza modular da planta do edificado e o predomínio de paredes estruturais em adobe e pedra, parece indicar que corresponde a uma construção oitocentista, que sofreu mudanças e ampliações ao longo das centúrias seguintes, observando-se várias divisórias internas em tijolo cerâmico e reboco de cimento, até atingir as características atuais.

Os trabalhos de arqueologia desenvolvidos no âmbito de um projeto de reabilitação urbana possibili- taram a observação de toda a sequência estratigráfica do local, assim como a deteção de vestígios relacionados com a evolução deste núcleo populacional e as mutações da malha urbana desde finais da Idade Média até à atualidade.

Destacamos em particular a identificação de quatro estruturas de combustão, associadas a acervos materiais enquadráveis entre os séculos XV-XVI, que corresponderão à primeira fase de ocupação deste espaço, e nos oferecem um vislumbre de algumas das atividades quotidianas dos obidenses nas centúrias de quatrocentos e quinhentos (Figura 1).

\section{A OLARIA}

A remoção dos pisos pertencentes ao edificado intervencionado, assim como de um conjunto de aterros (séc. XVII/XVIII), permitiu a identificação de um conjunto de quatro estruturas de combustão, muito afetadas pela construção do edifício e suas

1.ERA-Arqueologia, S.A.; geral@era-arqueologia.pt 
diversas remodelações até à atual requalificação, apresentando ainda danos mais próximos, cronologicamente, do términus do seu funcionamento (construção de um tanque no piso oo, abertura de interfaces de funcionalidade desconhecida e construção de um caneiro no piso -O1).

Embora muito afetadas, oferecendo-nos assim informações limitadas, tanto no que diz respeito à sua tipologia como ao seu funcionamento, foi possível concluir que correspondiam a quatro estruturas de combustão, encontrando-se estruturadas de modo similar, formadas por uma câmara de combustão de tendência sub-circular, algo ovalada, escavada diretamente no geológico, onde não foram identificados vestígios de grelha. Apresentam paredes estruturadas em barro, com cerca de $10 \mathrm{~cm}$ de espessura, com uma tonalidade avermelhada devido à combustão. É de referir que, ao contrário dos restantes, o forno no 2 apresenta um orifício circular situado na base da sua parede Sul, o qual fazia ligação ao exterior através de uma pequena valeta com paredes revestidas por telhas colocadas em cutelo, encontrando-se o interior preenchido por uma concentração abundante de cinzas. Este canal poderia tratar-se de um meio para abastecer a câmara de combustão com oxigénio, ou meramente uma saída para fumos. É igualmente de mencionar que o forno $\mathrm{n}^{\circ} 2$ mostra sinais de reconstrução, tendo-se verificado que as suas paredes internas foram restauradas com recurso à colocação de elementos pétreos em calcário, revestidos com cerâmica de construção, ladrilhos e argila, presentes nomeadamente na parede Norte, preenchendo uma fissura vertical.

No interior as estruturas de combustão encontravam-se entulhadas por uma sucessão de depósitos sedimentares intercalados entre argilas e camadas compactadas de carvões/cinzas, com presença escassa de elementos cerâmicos, possuindo o acervo recolhido uma cronologia tardo-medieval/ moderna (XV-XVI). Posteriormente, estes níveis foram cobertos por uma sucessão de aterros associados a um acervo que aponta para uma cronologia compreendida entre o século XVI e o século XX (Figura 2 e 3).

\section{CULTURA MATERIAL}

Do acervo material recuperado da Rua da Biquinha $\mathrm{n}$ ‥64, Óbidos, é possível discernir dois grandes conjuntos: os materiais correlacionáveis com os for-

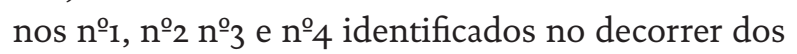

trabalhos de arqueologia e que, como tal, são vitais para a definição de cronologias de funcionamento destas estruturas e no aferir das produções e tipologias que seriam produzidas neste sítio; e as cerâmicas recolhidas de entre os níveis de aterro utilizados na desativação do espaço e remodelação do terreno para novos usos.

No primeiro conjunto encontramos uma forte presença de fabricos locais, e em particular produções de cerâmica comum ou de superfícies vidradas em tons de melado ou verde (óxidos de cobre ou ferro). No geral, as pastas apresentam cores castanha-avermelhadas (5YR 4/4 ou 7.5YR 8/4), sendo algo granulosas mas bem depuradas, o que denota um cuidado razoável na preparação e depuração dos barros. Nos depósitos relacionados com a desativação do forno 2, nomeadamente o nível [230] foram recolhidos vários fragmentos de panelas de bordo reto com lábio semicircular encimando um gargalo alto e corpo ovóide decorado com caneluras, acompanhadas de testos discoidais de lábio biselado simples e com pega central cilíndrica algo estrangulada.

Para além de peças de cozinha encontram-se também fragmentos contentores de fogo como candeias de forma troncocónica, algo achatada, paredes exvertidas e deformadas por modo a produzir um bico triangular. Nenhum dos exemplares observados apresentava asa ou pega vertical.

Todas são produções enquadráveis nos finais do século XV e inícios do XVI, podendo ser observados noutros contextos de produção oleira como aqueles observados no Largo das Olarias em Lisboa (PONCE, 2017, p. 4-5) .

Há igualmente a destacar os fragmentos de alguidar presentes no depósito [221], caracterizando-se estes por um bordo exvertido de lábio em aba semicircular ou espessado com lábio semicircular, e vestígios de engobe vermelho no anverso. Estas tipologias são tendencialmente atestadas nos finais do XV e inícios do XVI. A presença destes materiais no interior dos fornos poderá estar relacionada com a sua desativação e entulhar com lixo de produção oleira, sendo que estas tipologias estariam no repertório ali produzido. No entanto, é igualmente possível que alguns fragmentos estejam associados a tentativas de remodelar ou reparar a câmaras de combustão com fragmentos cerâmicos mais espessos e resistentes, sendo conhecidos outros casos similares, como o forno identificado no quarteirão dos Lagares e datado do século XVI (CASTRO et all, 2017: 1733). 
Os depósitos [316], [317] e [313] relacionados com o forno $\mathrm{n}^{\mathrm{o}} 3$ ofereceram cultura material similar composta, sobretudo, por fragmentos de bojos cerâmica comum pertencente a panelas e tachos. As primeiras mostram bordo reto com lábio semicircular encimando um gargalo alto e corpo ovóide decorado com caneluras. Os tachos mostram forma troncocónica com bordo invertido de lábio biselado. Ambas as tipologias são tendencialmente atestadas nos finais do XV e inícios do XVI e encontram paralelos nas produções do Largo das Olarias e Beco dos Lagares, e das peças identificadas na Rua em Óbidos. Por último os depósitos [705] e [712] no interior do forno $\mathrm{n}^{\circ} 4$ continham um número reduzido de fragmentos cerâmicos, pertencentes a bojos de panelas e exemplares de testos discoidais, similares aos recolhidos no forno $\mathrm{n}^{\circ} 2$ e, como tal, cronologicamente consentâneo com o mesmo.

No geral as cerâmicas recolhidas do interior dos fornos e dos depósitos relacionados com a sua desativação e abandono correspondem a peças de cozinha ou armazenamento, com alguns exemplares multifuncionais como os alguidares, ou para iluminação, como as candeias.

Perante este panorama, podemos assumir que esta produção oleira abasteceria o mercado local, focando-se nas necessidades dos habitantes de Óbidos e terras envolventes, sendo que algumas das peças de cerâmica comum e vidrada observadas em vários contextos modernos da cidade, como os das Rua Direita de Óbidos 54-58 (LIBERATO e RAMOS, 2017) poderão provir destas mesmas olarias.

O segundo conjunto engloba as produções provenientes dos depósitos utilizados no aterrar dos fornos ou das áreas envolventes mas que não correspondem a produtos locais, provindo de outros pontos do país ou sendo importadas de outros pontos da Europa. Este conjunto apresenta ainda um espectro cronológico mais amplo.

Associado ao abandono dos fornos, particularmente nos depósitos [612] e [616] encontramos vários fragmentos de peças de mesa de superfícies esmaltada. As pastas de tom amarelo pálido, granulosas e compactas, revestidas com um esmalte de estanho branco pouco espesso e baço, apontam para a sua natureza como produções sevilhanas do século XV e inícios do XVI (GUTIÉRREZ, 200o). Entre os exemplares identificados encontramos peças apenas esmaltadas, denominadas como louça malegueira ou "Plain White" acompanhadas de outras que apresentavam nas superfícies decoração pintada a tons de azul e manganês, de padrões decorativos geométricos, como linhas concêntricas intercaladas com bandas (Isabella Polichrome), ou temáticas vegetalistas ou fitomórficas a azul claro (Ibidem: 306). A presença de tais produções estará ligada com os hábitos aquisitivos da comunidade local, aqui representados nos descartes de lixos domésticos. Destaca-se a presença de importações de serviços de mesa do mercado hispano, nomeadamente peças esmaltadas a branco de Sevilha, presentes noutros contextos arqueológicos escavados em Óbidos (LIBERATO, 2017, p. 1595), e que permitiam aos locais complementar os seus serviços, formados por peças produzidas em locais similares ao sítio da Rua da Biquinha 54, com produções forâneas mais elaboradas.

Relacionadas com a contínua ocupação do espaço encontramos exemplares de faiança portuguesa, nomeadamente um fragmento recolhido no depósito [10o] da sala 1, correspondendo a fundo de prato, apresentando ao centro espiral em tom manganês, uma produção atribuível às olarias de Coimbra e datável de meados do século XVIII. Noutros pontos, nomeadamente, [203], [502], [508], [612], [617], foram recolhidos fragmentos de outras peças de faiança portuguesa, datadas de finais do século XVII e inícios do XVIII, apresentando decoração de semicírculos concêntricos ou motivo de contas a azul e vinhoso na aba (CASIMIRO, 2013 p.363).

As produções mais recentes identificadas são exemplares de faiança portuguesa coimbrã de tipo "ratinho", apresentando as superfícies decoradas com motivos vegetalistas em tom de verde e manganês. A estas juntam-se vários fragmentos de peças da fábrica de Sacavém, exibindo a sua marca no reverso, e a típica decoração monocromática de uma paisagem com uma estátua equestre. Ambos os conjuntos, integram-se cronologicamente no século $\mathrm{XX}$, marcando a adopção pela comunidade local das produções já claramente industriais que dominaram o mercado desde então.

A evolução e o contínuo uso deste espaço está bem demonstrado na presença destas produções do período moderno tardio e inícios da contemporaneidade. A aquisição de produções de faiança industrial sobretudo em áreas mais distantes dos grandes centros urbanos demonstra a expansão e impacto que estas novas produções tiveram no quotidiano destas populações.

A evolução e o contínuo uso deste espaço estão bem 
demonstrados na presença destas produções do período moderno tardio e inícios da contemporaneidade. A aquisição de produções de faiança industrial, sobretudo em áreas mais distantes dos grandes centros urbanos, demonstra a expansão e impacto que estas novas produções tiveram no quotidiano destas populações (Figura 4).

\section{CONCLUSÃO}

O sítio da Rua da Biquinha no. 64 aporta interessantes dados para o conhecimento da história da cidade de Óbidos.

Apresentando-se como um centro urbano de relevância regional, a confirmação da presença de produção oleira no local durante o século XV-XVI é, embora expectável, importante, confirmando-se assim a sua natureza como centro abastecedor não só das suas necessidades no que concerne ao vasilhame cerâmico, mas certamente dos acentamentos rurais envolventes. De facto, no que concerne à cultura cerâmica recuperada neste local, apenas as produções finas, nomeadamente as peças de mesa esmaltadas a estanho correspondem a produções importadas, e mesmo estas de mercados próximos como o hispano (Sevilha).

A restante cultura cerâmica recolhida do interior dos fornos e dos depósitos relacionados com a sua desativação e abandono correspondem a peças de cozinha ou armazenamento, com alguns exemplares multifuncionais como os alguidares, ou para iluminação como as candeias, as quais seriam comuns em todos os contextos habitacionais, podendo-se assumir, embora não confirmar sem os devidos estudos petrográficos, que algumas das peças de cerâmica comum e vidrada observadas em vários contextos modernos da cidade, como os das Rua Direita de Óbidos 54-58 (LIBERATO e RAMOS, 2017) poderão provir destas mesmas olarias.

De igual modo, a presença destes fornos oleiros numa área exterior ao perímetro amuralhado, insere-se claramente nas práticas medievais de colocar atividades perigosas ou insalubres fora das áreas habitacionais, normalmente em arrabaldes ou zonas periféricas. De facto, outros casos conhecidos no território nacional, são o forno identificado na Travessa de Nenhures em Palmela (possuindo igualmente uma câmara de combustão de plano sub-circular, e possuindo uma cronologia do século XVII); os dois fornos na Mata da Machada (onde foi inter- vencionado o denominado "forno grande" com uma planta retangular, provida de câmara de combustão, grelha e câmara de enfornamento formada por pequeno átrio (Torres, 1990). O outro forno de dimensões mais reduzidas, mostrava planta circular, sendo atribuída uma cronologia relativa ao século XVI (Santos, 2003, p.38)); o forno tardo-medieval (UE 215) da olaria da Porta da Lagoa (Évora, Portugal), escavado por baixo do Palácio de Sepúlvedas Além de responderem a questões de salubridade a colocação destas estruturas fora das muralhas poderá ter facilitado o acesso aos barreiros usados no abastecimento das olarias, o acesso a combustível vegetal ou facilitar o escoamento da produção para a vila ou territórios próximos. A eventual desativação destes fornos oleiros, por motivos que nos são de momento, alheios, parece ter levado a uma fase de abandono do lote, apenas quebrada com a construção do presente edificado e a sua reintegração na malha urbana de Óbidos. Assim é aceitável supor que nas imediações deste lote poderão encontrar-se outros vestígios similares ou outros elementos relacionados com a produção oleira.

\section{BIBLIOGRAFIA}

CASIMIRO, Tânia. (2013) - Faiança portuguesa: datação e evolução crono-estilística, Revista Portuguesa de Arqueologia, vol.16, Lisboa, pp. 351-367.

CASTRO, Anabela; PAULA, Nuno Amaral; de; TORRES, Joana.; CURADO, Tiago; TEIXEIRA, André, (2017) - Evidências de produção oleira nos séculos XVI e XVII no Largo das Olarias, Mouraria (Lisboa), ARNAUD, J. M. e MARTINS, A. (coords.) Arqueologia em Portugal: 2017-Estado da Questão, AAP, FLUL e NOVA/FCSH, Lisboa, pp. 1731-175o.

DORDIO, Paulo, TEIXEIRA, Ricárdo, SÁ, Anesrle. (2002) - Faianças do Porto e Gaia: o recente contributo da arqueologia: Itinerário da Faiança do Porto e Gaia, Lisboa, IPM.

GUTIÉRREZ, Alejandra. (200o) - Mediterranean Pottery: Wessex Households ( $13^{\text {th }}$ to $17^{\text {th }}$ Centuries), BAR British Series 306 .

LIBERATO, MARCO; SANTOS, HELENA; GOUFA, ELIANA (2017) - Quatro Intervenções de Arqueologia Preventiva em Óbidos, Almadan Online, II Série (21), Tomo 3, Centro de Arqueologia de Almada (https://issuu.com/almadan/ docs/al-madanonline21_3)

PONCE, Monica; NUNES, Tiago; PINTO, Marina; LOURENÇO, Marina; OLIVEIRA, Filipe (2017) - O sítio dos Lagares (Lisboa): um espaço pluri cultu(r)al. ARNAUD, J. M. e MARTINS, A. (coords.) Arqueologia em Portugal: 2017 - Estado da Questão, AAP, FLUL e NOVA/FCSH, Lisboa, pp. 1703-1714. 
SANTOS, Helena; LIBERATO, Marco; RAMOS, Romão (2017) - Resultados da Intervenção Arqueológica realizada nos №s 54 a 58 da Rua Direita, em Óbidos. ARNAUD, J. M. e MARTINS, A. (coords.) Arqueologia em Portugal: 2017 - Estado da Questão, AAP, FLUL e NOVA/FCSH, Lisboa, pp. 1593-1605.

SILVA, Manuela Silva (1994) - A Região de Óbidos na Época Medieval: estudos. Caldas da Rainha.
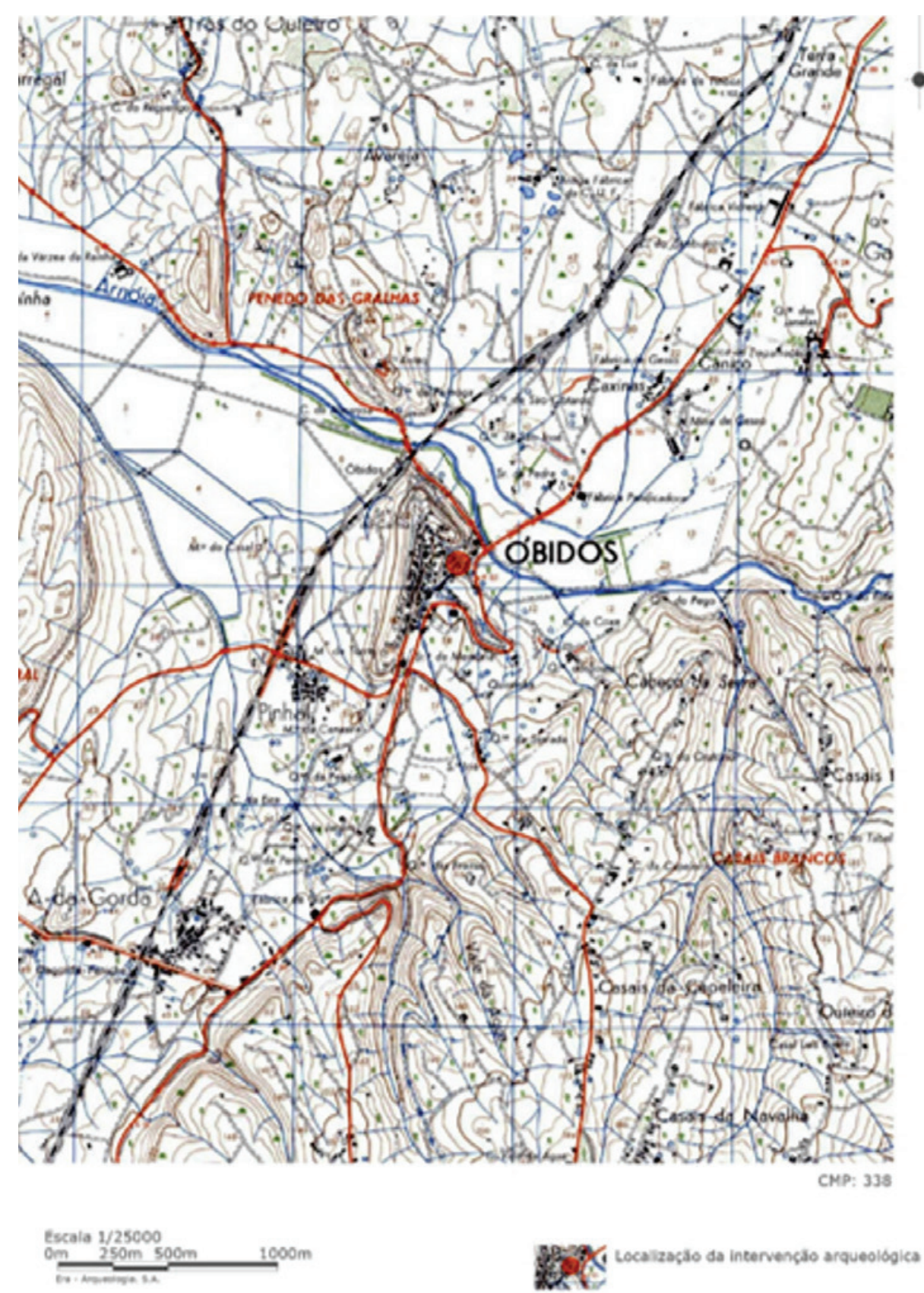

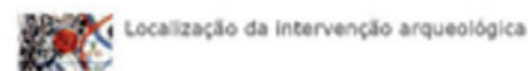

Figura 1 - Localização do local intervencionado em excerto da CMP, folha 338, à escala 1/2500o; Hugo Silva. 

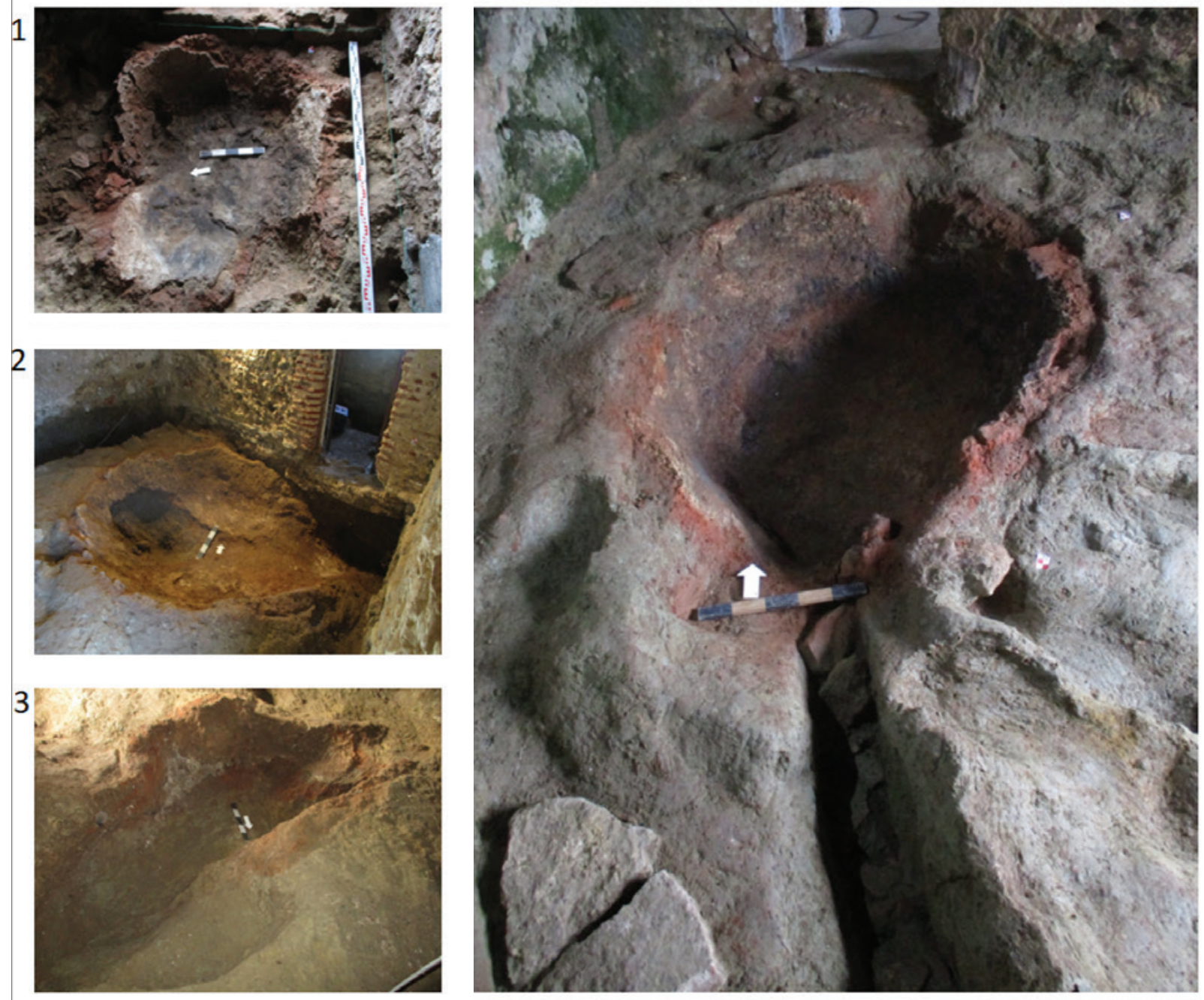

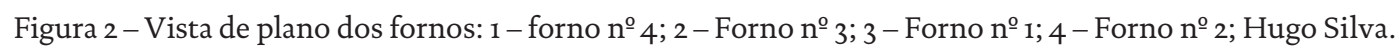


1

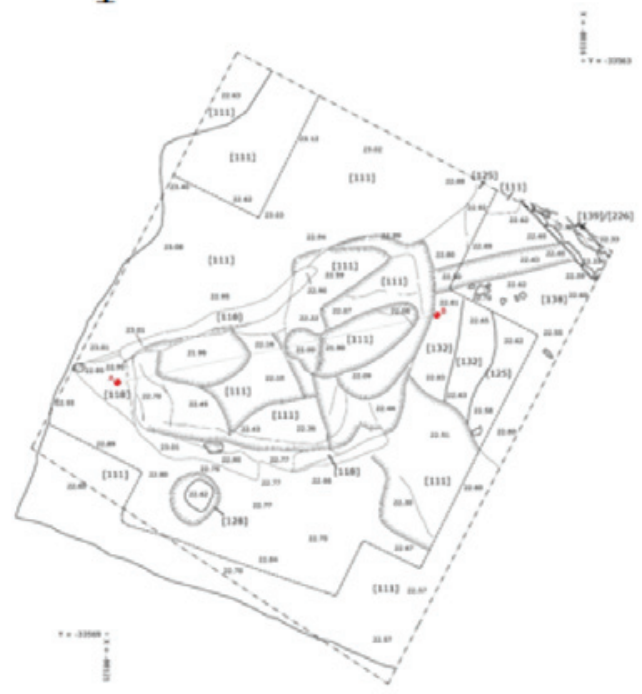

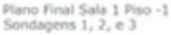
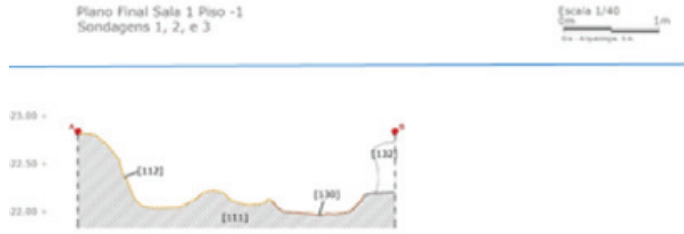

Secello Longtudinat do Formo
UE118 (Sudeste-Noroeste)

3

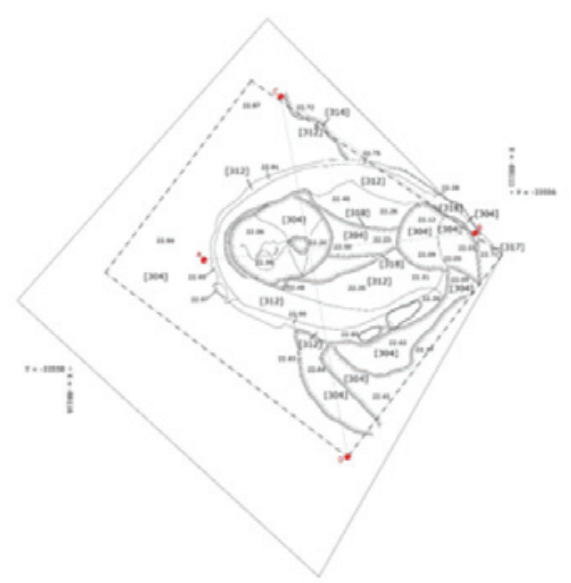

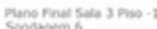
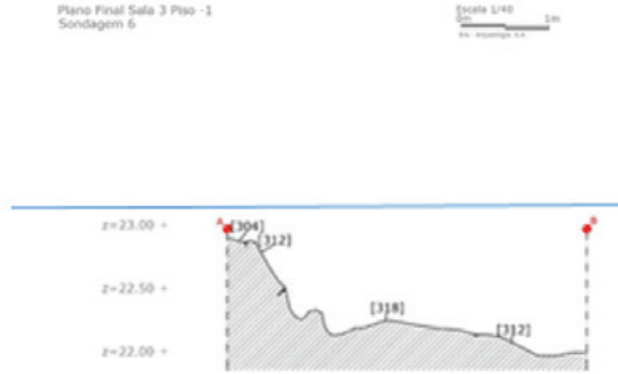
Seç30 Longitudinal do Forno
UE312 (Sudoeste-Nordeste)

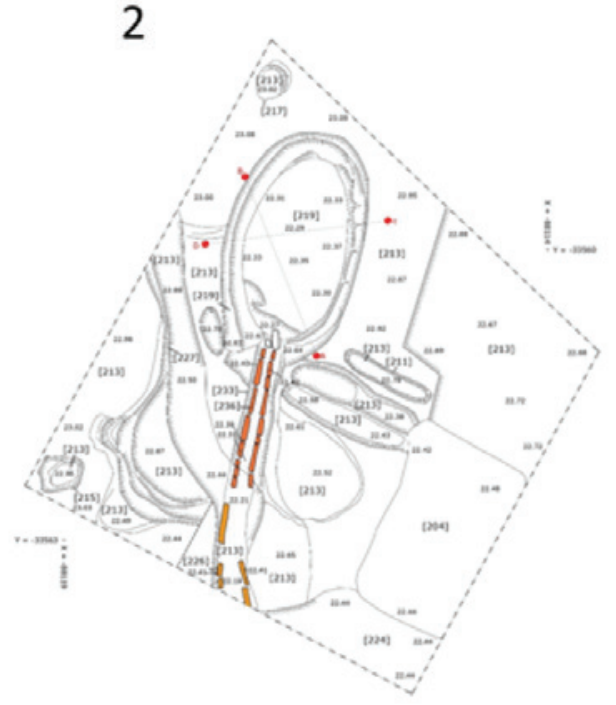

Plano Final Salo 2 Piso -1
Sondagens 4 es

Syatio yeo

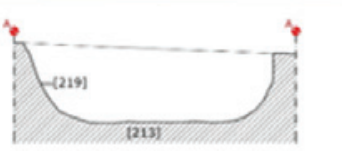

Secç̄o Longitudinal do Forno UE219 (Sul-Norte)

4
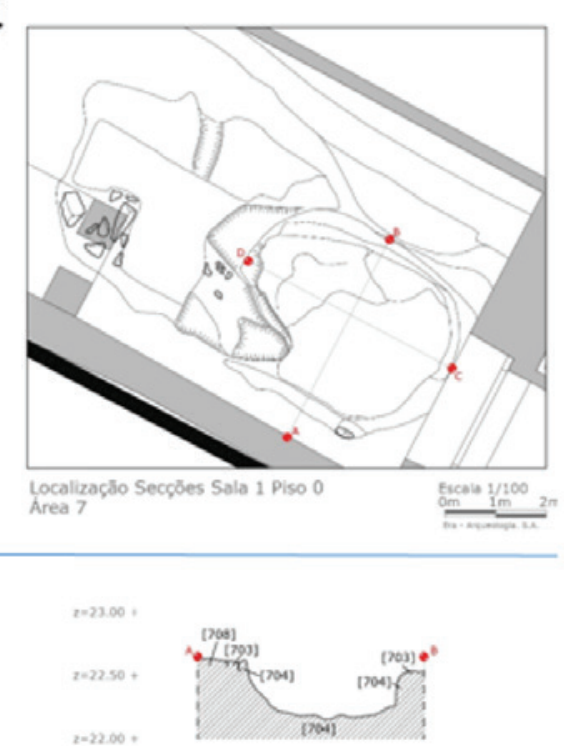

Secçăo Transversal do forno $n^{\circ} 4$ UE708, 703, 704

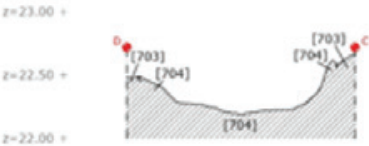

Seçăo Longitudinal do Forno $n^{\circ} 4$

Escalo $1 / 40$

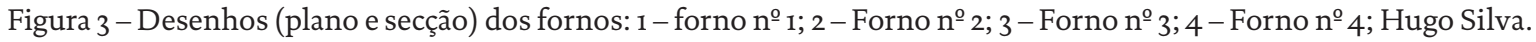



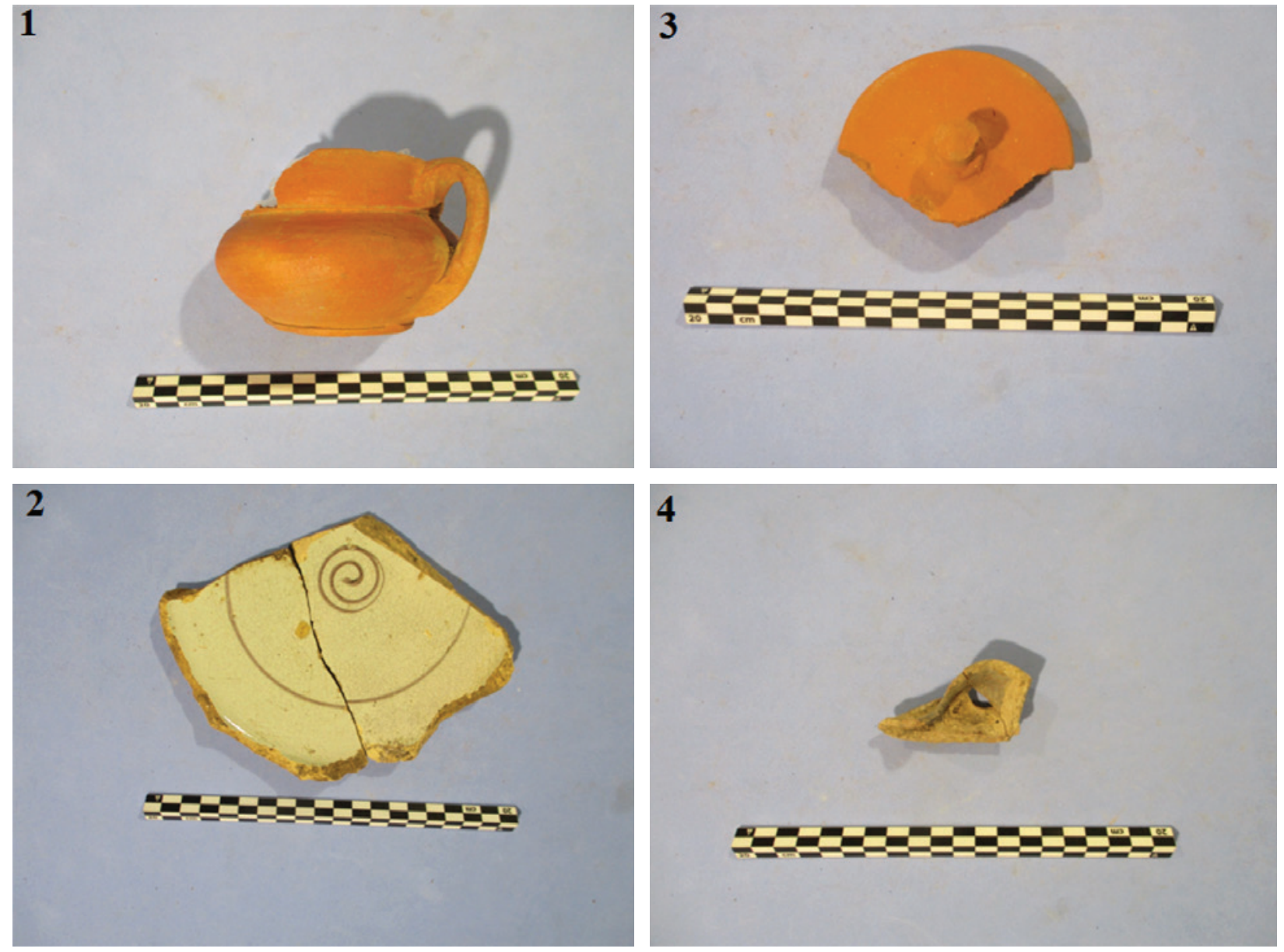

Figura 4 - Fragmentos cerâmicos: 1 - Púcaro (níveis de abandono do forno noำ $) ; 2$ - Fragmento de faiança (fundo de prato, em níveis de aterro da sala 1, piso -o1); 3 - Testo (recolhido em níveis de abandono do forno $\mathrm{n}^{\circ}$ 4); 4 - Fragmento de candeia (recolhida no forno nํㅜㄹ); Hugo Silva. 



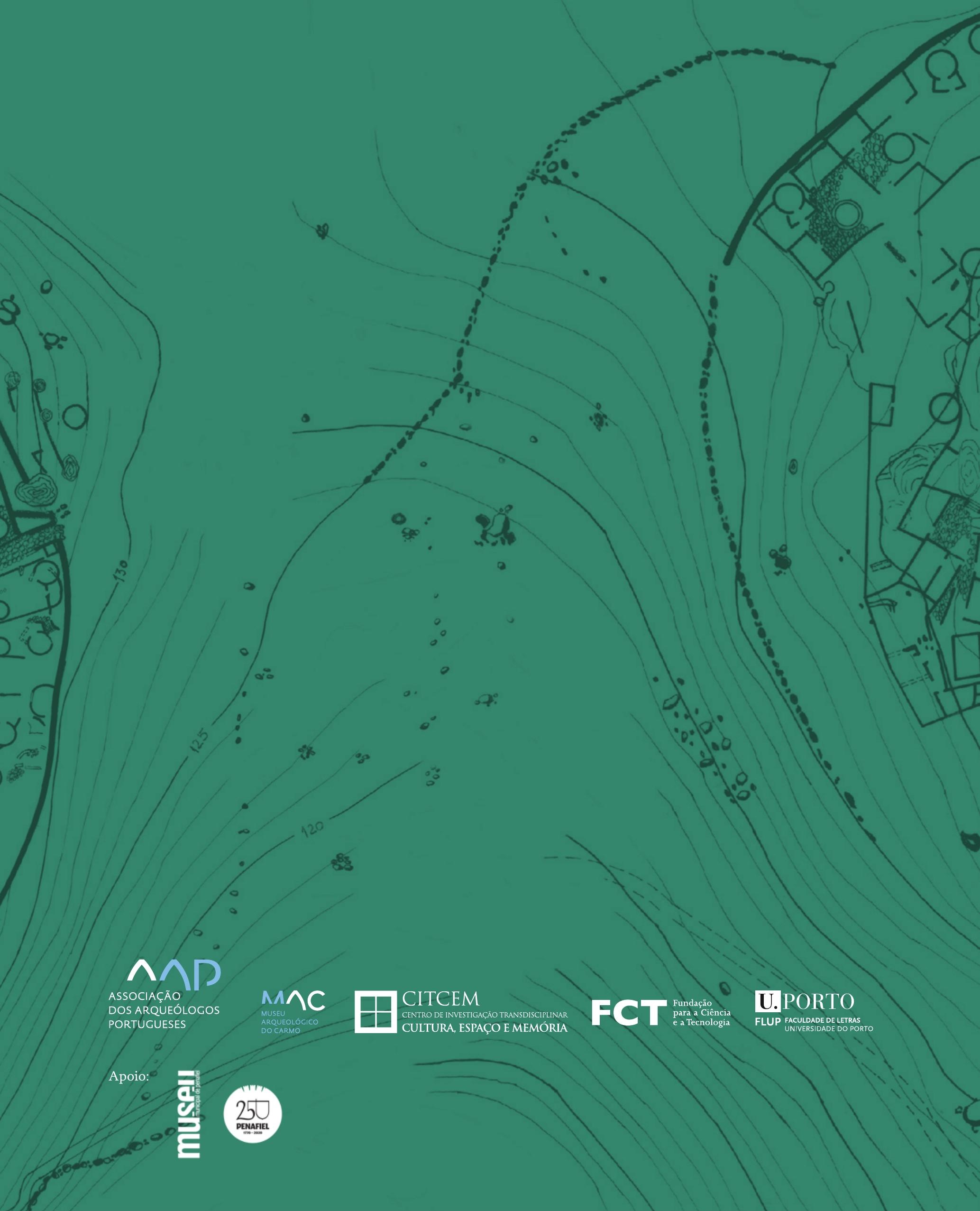

